\title{
Translation and psychometric testing of the Polish version of the Neonatal Extent of Work Rationing Instrument (NEWRI)
}

\author{
Anna Rozensztrauch ${ }^{1, A-F} \oplus$, Izabella Uchmanowicz ${ }^{2, A, E-F} \oplus$, Barbara Suchowska ${ }^{1, B-D \oplus}$, \\ Robert Śmigiel ${ }^{1, A, C, E-F} \oplus$ \\ ${ }^{1}$ Department of Paediatrics, Faculty of Health Sciences, Medical University, Wrocław, Poland \\ ${ }^{2}$ Department of Clinical Nursing, Faculty of Health Sciences, Medical University, Wrocław, Poland \\ A - Research concept and design, B - Collection and/or assembly of data, C - Data analysis and interpretation, \\ $D$ - Writing the article, E - Critical revision of the article, F - Final approval of article
}

Rozensztrauch A, Uchmanowicz I, Suchowska B, Śmigiel R. Translation and psychometric testing of the Polish version of the Neonatal Extent of Work Rationing Instrument (NEWRI). Ann Agric Environ Med. 2021; 28(1): 94-98. doi: 10.26444/aaem/116907

\begin{abstract}
Objective. The aim of the study was to perform translation and cultural adaptation, as well as to assess the validity and reliability of the Polish version of the Neonatal Extent of Work Rationing Instrument (NEWRI) questionnaire for evaluating care rationing in neonatal intensive care units (NICUs) in Poland.

Materials and Method. Participants were prospectively recruited at the University Clinical Hospital in Wroclaw, Poland, and the study conducted from January 2018 - June 2018. The adaptation process involved translation of survey items following the guidelines for cross-cultural translation and evaluation of psychometric properties, as well as an assessment of construct validity, reliability, and internal consistency of the NEWRI using Cronbach's alpha.

Results. 113 professionally active nurses $(n=90)$ and midwives $(n=23)$ were enrolled in the study. Cronbach's alpha for the entire instrument was 0.982. Results for subscales: life support and technology-oriented nursing care - Cronbach's alpha - 0.95, parental support and teaching and infant comfort care -0.95 , patient surveillance -0.92 , care coordination and discharge planning - 0.79. All items of the questionnaire were found to have a positive discriminatory power.

Conclusions. The present findings indicate a high level of reliability and validity of the translated questionnaire, fully comparable to that of the original. The questionnaire can be used for evaluating care rationing in NICUs.
\end{abstract}

\section{Key words}

psychometric evaluation, Polish validation study, neonatal nursing, care rationing, Neonatal Extent of Work Rationing Instrument

\section{INTRODUCTION}

The old principle 'Salus aegroti suprema lex' - 'the wellbeing of the patient is the supreme law' - is an unquestionable foundation of all the ethical principles of patient care. In practice, however, the interpretation of the patient's best interest often proves to be difficult, if not impossible.

New knowledge and great advances made in the study of the foetus and neonate mean that newborns in an increasingly severe clinical condition are being saved in neonatal wards. The specific health and care-related problems of the neonatal population require special knowledge, competences, and skills from medical personnel, also in terms of work organization and patient discharge. Following discharge, parents must not only provide normal care to their baby, but also ensure the continuation of multidisciplinary health care initiated during hospitalization $[1,2]$.

Missed care, as defined by the American pioneers Kalisch et al. [3], involves any aspect of required patient care that is omitted or delayed. According to the authors, nursing care rationing occurs when the available resources are insufficient for the provision of required patient care.

As demonstrated by a literature review, the problem of

Address for correspondence: Anna Rozensztrauch, Department of Pediatrics, Faculty of Health Sciences, Wrocław Medical University, Wrocław, Poland E-mail: anna.rozensztrauch@umed.wroc.pl

Received: 26.11.2019; accepted: 20.01.2020; first published:04.02.2020 missed care is prevalent both in Poland and worldwide. The review of studies on care rationing shows that as many as $55-98 \%$ of nurses omit $\geq 1$ nursing activities in patient care. Patient and family education and provision of emotional support are the most commonly omitted activities, attending to the patient's physiological needs - the least. Missed care is predicted more strongly by organizational factors, including poor working conditions and staff shortages, rather than by nurses' personality traits [4-7].

The very definition of care rationing provokes the question about whether it is ethical to omit care for newborns and their mothers to any extent. The broad scope of responsibilities and the limited resources force nurses to prioritize and focus on the most essential activities, while omitting or minimizing other duties. Decisions are moral dilemmas, resolved without the patient's participation $[8,9]$. How, then, are these decisions made?

As emphasized by Scheunemann and White [10], rationing in health care is associated with a very well-defined part of allocation policy. Medical staff are required to make an informed decision on why some patients are excluded from an activity, while some are not, bearing in mind that the activity may save or extend the life of a patient or significantly increase the quality of life. Resource allocation and nursing care rationing are related concepts. In accordance with the care rationing philosophy by Scott et al. [11], nursing activities involve diagnostics, treatment, prevention, rehabilitation, 
and emotional support. The activities as such are not treated as equal, but are all expected by the patients.

Nursing staff shortages, widespread in Polish hospitals, undoubtedly exacerbate the problem of nursing care rationing. Many institutions implement strategies to cut health care costs, involving reductions of nursing staff numbers and of resources allocated to intensive care units. A review of available studies showed that staff shortages contribute to adverse patient outcomes [12].

Moreover, a loweing of the quality of nursing care and nurses' skills was associated with an increased number of adverse events and negative treatment outcomes. When fewer nurses must provide care to a larger number of patients, each nurse has less time to perform all their duties, thus being forced to prioritize tasks and/or omit some of them entirely $[4,13]$. Without sufficient resources and management support, nurses start rationing care and rushing through their tasks, which affects the quality of their work.

Without a doubt, 'incomplete care' for neonatal patients is a growing problem, both clinical and ethical, requiring empirical studies as well as an ethical reflection by decisionmakers in health care [14].

The development of a Polish version of the questionnaire to assess nursing care rationing in neonatal wards will surely assist in identifying the issue and investigating it further. To date, a validated version of the Neonatal Extent of Work Rationing Instrument (NEWRI) in Polish is not available and a need therefore exists for a translation, both for research and clinical activity.

\section{OBJECTIVE}

The purpose of the study was to perform an adaptation of the NEWRI questionnaire evaluating neonatal nursing care rationing into Polish, and to assess its utility through psychometric evaluation.

\section{MATERIALS AND METHOD}

The translation and psychometric testing of the NEWRI instrument was completed in 6 steps: 1) forward translation, 2) revision, 3) back translation, 4) revision, 5) pilot testing, 6) data collection and psychometric testing. Steps 1-4 included the back-translation process.

Study participants. The NEWRI pilot-testing was performed between January - June 2018, in a group of 113 respondents, of whom $79 \%$ were Registered Nurses (RNs) ( $n=90)$ and $21 \%$ were Registered Midwives (RMs) $(n=23)$, all working at Neonatal Intensive Care Units (NICUs), at the University Clinical Hospital in Wrocław, Poland. The study group was recruited using targeted selection. For the psychometric testing of the questionnaire, participants were included if they stated that they spent most of their working time on the unit. The time it took participants to complete the quiestionaire was not measured. All respondents were instructed that participation was strictly voluntary and anonymous, and were informed of the study purpose. Lack of consent to participate was the only exclusion criterion. The participants completed a questionnaire that was a Polish translation of the full original NEWRI questionnaire. The Polish version also had a visual format identical to that developed by the author of the original. Psychometric analyses only included fully completed questionnaires.

Ethical considerations. The study was approved by the Bioethics Committee of the Medical University in Wrocław, Poland (Approval No. KB-394/2018). All respondents provided written informed consent prior to participation in the study. In the national survey, participation equaled written informed consent.

Research Tool. The Neonatal Extent of Work Rationing Instrument (NEWRI) questionnaire is an instrument for the evaluation of nursing care rationing in neonatal wards, published by Rochefort in 2010 [13]. It comprises 59 items related to nursing activities in neonatal care. Four subscales can be identified:

1) life support and technology-oriented nursing care (15 items);

2) parental support and teaching and infant comfort care (12 items);

3) patient surveillance (7 items);

4) care coordination and discharge planning (6 items).

Each item is rated using a 1-4 scale, where 1 = 'very rarely', 2 - 'rarely', 3 - 'often', and 4 - 'very often'. Subsequently, results are transposed as necessary using a 4-point Likerttype scale. Higher scores in each subscale indicate more difficulty in performing the necessary nursing tasks, based on the patients' condition and/or needs, due to insufficient time or resources (e.g. support, assist or encourage parents in performing infant's care, assess patient signs and symptoms).

Translation and Language Validation. The language validation procedure was carried out in accordance with published guidelines $[15,16]$, following formal, written approval by the original author. The importance of the 2 main parts of the translation, language and content, was emphasized. Each question from the English original version was translated into Polish by 2 bilingual independent translators; their translation was then combined into one Polish version. The second step was to discuss and revise the translation of the Polish version. This was carried out by designated experts, one of whom worked in clinical practice (NICUs) and another as a researcher at the University Hospital. Neither of these evaluators had seen the original version of the survey. Their suggestions, which were minor, were then taken into consideration. A professional translator further reviewed and corrected this version to ensure that there were no remaining linguistic inconsistencies, which might have occurred during translation from English into Polish.

The back-translation was carried out by a professional translator who had not seen the original version of the instrument. The level of agreement with the English original version was considered good. Finally, the English version was translated back into the Polish language by two bilingual $\mathrm{PhD}$-prepared nurses (blinded to the previous Polish version, as well as the original English version). All versions of the instrument included 59 questions. As the meanings of each item remained the same as in the original, and no text or item was rated as different in terms of wording and content, the translated instrument was used in a pilot study (Supp. 1). 
Statistical analysis. Statistical data analyses were performed using $\mathrm{R}$ package, version 3.4.2. (R Foundation for Statistical Computing, Vienna, Austria) [17]. Internal consistency (IC) was checked with Cronbach's alpha coefficient and discriminatory power was calculated as the deleted item-total correlation (ITC). Cronbach's alpha ( $\alpha$ ) values should optimally range between the recommended values of $0.60-0.90$. The following thresholds for internal consistency were used: $0.9 \leq a-$ excellent; $0.8 \leq a<0.9-$ good; $0.7 \leq a<0.8$ - acceptable; $0.6 \leq a<0.7$ - questionable; $0.5 \leq a<0.6$ - poor; and $a<0.5$ - unacceptable. All items of the Polish version of the NEWRI were assessed using this approach, and Cronbach's a values $>0.70$ were considered satisfactory.

\section{RESULTS}

Socio-demographic data. Respondents' characteristics including their gender, age, marital status, place of residence, type of education, profession, work experience as a nurse/ midwife and work experience in the current place of employment, are summarized in Table 1.

Internal consistency analysis. Internal consistency for the entire scale, as measured by Cronbach's alpha, was 0.982, which indicates the instrument is highly reliable. For the 'life support and technology-oriented nursing care' subscale, Cronbach's alpha was 0.958 (Tab. 2), for 'parental support, and teaching and infant comfort care; - 0.951 (Tab. 3), 'patient surveillance' - 0.928 (Tab. 4), 'care coordination and discharge planning' -0.798 (Tab. 5).

The results were reproducible and did not occur randomly. Alpha values above 0.7 are considered indicative of a reliable scale [18]. All questionnaire items were found to have a positive discriminatory power, i.e. a positive correlation with other items, which is a very good result.

\section{DISCUSSION}

The testing of the NEWRI instrument from the English version into Polish was successfully carried out in 6 steps which included a back-translation process and psychometric testing. To date, 2 questionnaires exist for surveying missed nursing care: the Basel Extent of Rationing of Nursing Care (BERNCA) [19] and the Perceived Implicit Rationing of Nursing Care (PIRNCA) [20] (currently undergoing Polish adaptation), but neither is specific to NICUs. Without appropriate evidence to demonstrate that nursing care can be compromised due to a poor working environment, staff shortages, or insufficient resource allocation, it is difficult to secure the support required to improve these factors. No previous studies have described the association between the characteristics of the staff and the working environment on the one hand, and care rationing in NICUs on the other. Any similar studies only involved adult surgical and intensive care patients $[21,22]$.

Therefore, the primary motivation for adapting the NEWRI questionnaire was a need resulting from the lack of a properly constructed instrument for measuring the issue. The performed analyses confirmed that the Polish version of the NEWRI fulfills the required reliability and validity
Table 1. Respondents' characteristics $(n=113)$

\begin{tabular}{|c|c|c|}
\hline Characteristic & & Values \\
\hline \multirow{2}{*}{ Gender } & Female & $111(98.23 \%)$ \\
\hline & Male & $2(1.77 \%)$ \\
\hline \multirow{4}{*}{ Age group } & $20-30$ years & $31(27.43 \%)$ \\
\hline & $31-40$ years & $35(30.97 \%)$ \\
\hline & $41-50$ years & $44(38.94 \%)$ \\
\hline & $51-60$ years & $3(2.65 \%)$ \\
\hline \multirow{3}{*}{ Marital status } & Married & $74(65.49 \%)$ \\
\hline & Divorced & $9(7.96 \%)$ \\
\hline & Single & $30(26.55 \%)$ \\
\hline \multirow{4}{*}{ Place of residence } & Urban $>200,000$ residents & $49(43.36 \%)$ \\
\hline & Urban $25-200,000$ residents & $33(29.20 \%)$ \\
\hline & Urban $<25,000$ residents & $9(7.96 \%)$ \\
\hline & Rural & $22(19.47 \%)$ \\
\hline \multirow{3}{*}{ Education level } & Vocational & $8(7.08 \%)$ \\
\hline & Bachelor's degree & $52(46.02 \%)$ \\
\hline & Master's degree & $51(45.13 \%)$ \\
\hline \multirow{2}{*}{ Profession } & Nurse & $91(80.53 \%)$ \\
\hline & Midwife & $22(19.47 \%)$ \\
\hline \multirow{6}{*}{$\begin{array}{l}\text { Work experience as a nurse/ } \\
\text { midwife }\end{array}$} & Up to 1 year & $7(6.19 \%)$ \\
\hline & $2-5$ years & $24(21.24 \%)$ \\
\hline & $6-10$ years & $21(18.58 \%)$ \\
\hline & $11-20$ years & $29(25.66 \%)$ \\
\hline & $21-30$ years & $31(27.43 \%)$ \\
\hline & more than 35 years & $1(0.88 \%)$ \\
\hline \multirow{6}{*}{$\begin{array}{l}\text { Work experience in the current } \\
\text { place of employment }\end{array}$} & Up to 1 year & $15(13.27 \%)$ \\
\hline & $2-5$ years & $33(29.20 \%)$ \\
\hline & $6-10$ years & $26(23.01 \%)$ \\
\hline & $11-20$ years & $25(22.12 \%)$ \\
\hline & $21-30$ years & $13(11.50 \%)$ \\
\hline & more than 35 years & $1(0.88 \%)$ \\
\hline
\end{tabular}

criteria, and can therefore be used for measuring the extent of nursing care rationing in NICUs.

The reliability of the Polish version of the NEWRI was tested by calculation of Cronbach's alpha and discriminatory power. Cronbach's alpha is a measure of an instrument's internal consistency. According to literature data, Cronbach's alpha values should optimally exceed 0.90 . The following thresholds for results are used: $\geq 0.80$ - good, $\geq 0.70-$ acceptable, $\geq 0.60$ questionable, $\geq 0.50$ - poor, and $\leq 0.50$ unacceptable [23]. In the presented study, Cronbach's alpha for the Polish version was 0.98 , which is a very high value. For the 4 subscales identified in the analysis, the values ranged between $0.79-0.95$. Similar alpha values were obtained by the authors of the original questionnaire, Rochefort and Clarke [13] (for life support and technology-oriented nursing care subscale -0.93 , parental support and teaching and infant comfort care -0.93 , patient surveillance -0.83 , and care coordination and discharge planning -0.81 ). Considering the internal consistency results obtained both by the authors of the presented study and by Rochefort and Clarke [13], with alpha values above 0.70 found for all subscales confirming a good level of reliability and validity, the scale is recommended for use in NICUs. 
Anna Rozensztrauch, Izabella Uchmanowicz, Barbara Suchowska, Robert Śmigiel. Translation and psychometric testing of the Polish version of the Neonatal Extent...

Table 2. Cronbach's alpha values for 'life support and technology-oriented nursing care' subscale

\begin{tabular}{|c|c|c|}
\hline Item & $\begin{array}{l}\text { Alpha value with } \\
\text { the item excluded }\end{array}$ & $\begin{array}{l}\text { Discriminatory } \\
\text { power }\end{array}$ \\
\hline Bottle feed an infant. & 0.956 & 0.684 \\
\hline Tube feed an infant through a nasogastric, naso-jejunal, gastrostomy or jejunostomy tube. & 0.955 & 0.726 \\
\hline Administer total parenteral nutrition (i.e. TPN). & 0.954 & 0.787 \\
\hline $\begin{array}{l}\text { Perform or assist with medical procedures, treatments or diagnostic tests (e.g. dialysis, peritoneal dialysis, ECG, ECMO, } \\
\text { phototherapy or abdominal, lumbar and/or pleural puncture or tap, etc.). }\end{array}$ & 0.955 & 0.752 \\
\hline Prepare and administer a blood transfusion or blood products. & 0.953 & 0.834 \\
\hline Take or obtain a venous, arterial, capillary, urinary, faecal or other sample for laboratory analysis within a prescribed time. & 0.953 & 0.825 \\
\hline $\begin{array}{l}\text { Insert or assist with the insertion of an oropharyngeal or nasopharyngeal airway, an endotracheal tube or a tracheostomy or with } \\
\text { initiation of mechanical ventilation. }\end{array}$ & 0.952 & 0.875 \\
\hline Collaborate with or insert a peripheral, central or umbilical venous and/or arterial catheters, or perfusions and / or a PICC line. & 0.953 & 0.859 \\
\hline Insert or assist with the insertion of nasogastric, thoracic, peritoneal, urinary, or other tubes. & 0.952 & 0.864 \\
\hline $\begin{array}{l}\text { Perform care specific to endotracheal tubes, tracheostomies or ventilator therapy (e.g. verify tube and patient positioning, } \\
\text { suction secretions, perform mouth care or chest physiotherapy, verify or change tubes or ventilator settings, etc.). (Does not } \\
\text { apply to my nursing unit: }\end{array}$ & 0.953 & 0.817 \\
\hline $\begin{array}{l}\text { Perform care for patients with peripheral, arterial or umbilical venous and/or arterial lines or a PICC line (e.g. verify insertion site } \\
\text { and catheter positioning, verify patency, change dressings or tubing, monitor rate, type and quantity of solution, etc.). }\end{array}$ & 0.953 & 0.862 \\
\hline $\begin{array}{l}\text { Perform care for patients with nasogastric, thoracic, peritoneal, urinary, suprapubic tubes or surgical drains (e.g. inspect and } \\
\text { clean skin and insertion site, verify tube and drainage system positioning, secure connections, assess patency, monitor drainage } \\
\text { characteristics, irrigate the tube, change dressings, verify suction, empty drainage bag or system, etc.). }\end{array}$ & 0.953 & 0.856 \\
\hline $\begin{array}{l}\text { Perform care specific to splints, casts, tractions or restraints (e.g. assess skin integrity, warmth, colour, sensation, pulses and } \\
\text { capillary refill, mobilize and position the patient and the equipment, change dressings, etc.). }\end{array}$ & 0.96 & 0.492 \\
\hline
\end{tabular}

Table 3. Cronbach's alpha values for the 'parental support, and teaching and infant comfort care' subscale

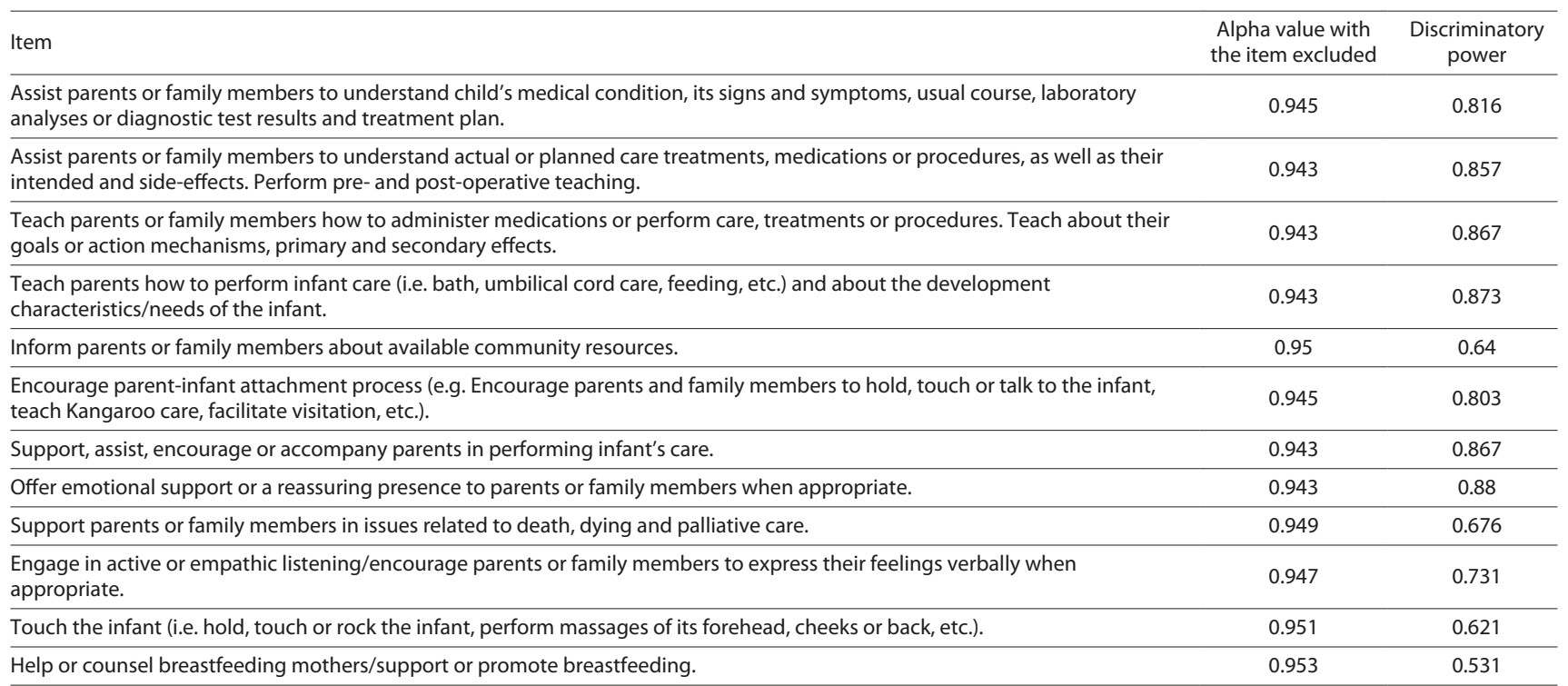

Table 4. Cronbach's alpha values for the 'patient surveillance' subscale.

\begin{tabular}{|c|c|c|}
\hline Item & $\begin{array}{l}\text { Alpha value with } \\
\text { the item excluded }\end{array}$ & $\begin{array}{l}\text { Discriminatory } \\
\text { power }\end{array}$ \\
\hline Assess infant development (e.g. weight, height, gestational age, head circumference, etc.). & 0.917 & 0.763 \\
\hline Perform neonatal physical exam, monitor physiological/haemodynamic function, vital signs, intake and output. & 0.905 & 0.885 \\
\hline Monitor results of laboratory analyses/diagnostic tests. & 0.93 & 0.634 \\
\hline Assess patient's signs and symptoms. & 0.904 & 0.899 \\
\hline $\begin{array}{l}\text { Monitor intended and side-effects of medications or treatments, including signs of medication toxicity, allergic, or transfusion } \\
\text { reactions or shock. }\end{array}$ & 0.916 & 0.78 \\
\hline $\begin{array}{l}\text { Inspect the skin, mucous membranes and eyes to prevent ulcerations, wounds or infections, and to detect changes in } \\
\text { colouration (e.g. jaundice, erythema), temperature or oedema. }\end{array}$ & 0.912 & 0.821 \\
\hline Regularly modify infant's position to prevent musculoskeletal abnormalities associated with immobility or poor positioning. & 0.931 & 0.629 \\
\hline
\end{tabular}


Table 5. Cronbach's alpha values for the 'care coordination and discharge planning' subscale

\begin{tabular}{|c|c|c|}
\hline Item & $\begin{array}{l}\text { Alpha value with } \\
\text { the item excluded }\end{array}$ & $\begin{array}{l}\text { Discriminatory } \\
\text { power }\end{array}$ \\
\hline $\begin{array}{l}\text { Communicate to the medical team relevant information/abnormal findings about infant health status, development and } \\
\text { response to medications, treatments, laboratory analyses/diagnostic tests. }\end{array}$ & 0.83 & 0.261 \\
\hline Participate in mult-disciplinary team meetings or in meetings with the medical team and the family. & 0.76 & 0.579 \\
\hline $\begin{array}{l}\text { Plan or organize patient's discharge, follow-up, appointments, transport or transfer to home, operating theatre, another nursing } \\
\text { unit/another hospital. }\end{array}$ & 0.725 & 0.714 \\
\hline $\begin{array}{l}\text { Organise or coordinate patient care services (e.g. organize diagnostic tests/medical, social services or psychological } \\
\text { consultations, pastoral visits; obtain instruments/medical equipment, etc.). }\end{array}$ & 0.72 & 0.737 \\
\hline Transfer or transport an infant to another nursing unit/ operating theatre/another hospital. & 0.775 & 0.513 \\
\hline Collaborate to perform an exchange transfusion. (Does not apply to my nursing unit: ___ $)$. & 0.77 & 0.537 \\
\hline
\end{tabular}

\section{CONCLUSIONS}

The Polish version of the NEWRI questionnaire is a useful tool for describing and monitoring the extent of neonatal nursing care rationing. Further studies are warranted to investigate the determinants of nursing care rationing in neonatal intensive care units.

\section{Acknowledgements}

The authors express their thanks to all respondents for their contributions in this research. Certified English language services were provided by a highly qualified academic native English speaker. The authors also thank Dr. Christian M. Rochefort for sharing the original version of NEWRI instrument.

\section{Funding source}

This study was conducted under a research project funded by the Ministry of Science and Higher Education of Poland as a part of a statutory grant of the Wroclaw Medical University for maintaining research potential (no. SUB.E020.19.003).

\section{Declaration of conflict of interest}

The authors declare no conflicts of interest.

There were no other contributors to the article than the authors, nor was there any assistance in writing the study.

\section{REFERENCES}

1. Trajkovski S, Schmied V, Vickers M, Jackson D. Neonatal nurses' perspectives of family-centred care: a qualitative study. J Clin Nurs. 2012 Sep; 21(17-18): 2477-87.

2. Alderdice F, Gargan P, McCall E, Franck L. Online information for parents caring for their premature baby at home: A focus group study and systematic web search. Health Expect. 2018 Aug; 21(4): 741-51.

3. Kalisch BJ. Missed nursing care: a qualitative study. J Nurs Care Qual. 2006 Dec; 21(4): 306-13; quiz 314-5.

4. Schubert M, Glass TR, Clarke SP, Aiken LH, Schaffert-Witvliet B, Sloane $\mathrm{DM}$, et al. Rationing of nursing care and its relationship to patient outcomes: the Swiss extension of the International Hospital Outcomes Study. Int J Qual Health Care. 2008 Aug; 20(4): 227-37.

5. Schubert M, Clarke SP, Aiken LH, de Geest S. Associations between rationing of nursing care and inpatient mortality in Swiss hospitals. Int J Qual Health Care. 2012 Jun; 24(3): 230-8.

6. Kalisch BJ, Xie B, Dabney BW. Patient-reported missed nursing care correlated with adverse events. Am J Med Qual. 2014 Oct; 29(5): 415-22.
7. Carthon JMB, Lasater KB, Sloane DM, Kutney-Lee A. The quality of hospital work environments and missed nursing care is linked to heart failure readmissions: a cross-sectional study of US hospitals. BMJ Qual Saf. 2015 Apr; 24(4): 255-63.

8. Larcher V, Craig F, Bhogal K, Wilkinson D, Brierley J, Royal College of Paediatrics and Child Health. Making decisions to limit treatment in life-limiting and life-threatening conditions in children: a framework for practice. Arch Dis Child. 2015 May; 100 Suppl 2: s3-23.

9. Papastavrou E, Andreou P, Vryonides S. The hidden ethical element of nursing care rationing. Nurs Ethics. 2014 Aug; 21(5): 583-93.

10. Scheunemann LP, White DB. The Ethics and Reality of Rationing in Medicine. Chest. 2011 Dec; 140(6): 1625-32.

11. Scott PA, Harvey C, Felzmann H, Suhonen R, Habermann M, Halvorsen $\mathrm{K}$, et al. Resource allocation and rationing in nursing care: A discussion paper. Nurs Ethics. 2019; 26(5): 1528-39.

12. Griffiths P, Recio®Saucedo A, Dall'Ora C, Briggs J, Maruotti A, Meredith $\mathrm{P}$, et al. The association between nurse staffing and omissions in nursing care: A systematic review. J Adv Nurs. 2018 Jul; 74(7): 1474-87.

13. Rochefort CM, Clarke SP. Nurses' work environments, care rationing, job outcomes, and quality of care on neonatal units. J Adv Nurs. 2010 Oct; 66(10): 2213-24.

14. Rochefort CM, Rathwell BA, Clarke SP. Rationing of nursing care interventions and its association with nurse-reported outcomes in the neonatal intensive care unit: a cross-sectional survey. BMC Nurs. 2016; 15: 46.

15. Beaton DE, Bombardier C, Guillemin F, Ferraz MB. Guidelines for the process of cross-cultural adaptation of self-report measures. Spine. 2000 Dec 15; 25(24): 3186-91.

16. Gjersing L, Caplehorn JR, Clausen T. Cross-cultural adaptation of research instruments: language, setting, time and statistical considerations. BMC Med Res Methodol. 2010 Feb 10; 10: 13.

17. R Core Team. R: A language and environment for statistical computing. R Foundation for Statistical Computing [Internet]. Vienna, Austria; 2017. Available from: https://www.R-project.org/

18. Ferreira MBG, Haas VJ, Dantas RAS, Felix MM dos S, Galvão CM. Cultural adaptation and validation of an instrument on barriers for the use of research results 1. Rev Lat Am Enfermagem [Internet]. 2017 Mar 9 [cited 2019 Jan 16];25. Available from: https://www.ncbi.nlm. nih.gov/pmc/articles/PMC5363328/

19. Schubert M, Glass TR, Clarke SP, Schaffert-Witvliet B, De Geest S. Validation of the Basel Extent of Rationing of Nursing Care instrument. Nurs Res. 2007 Dec; 56(6): 416-24.

20. Jones TL. Validation of the Perceived Implicit Rationing of Nursing Care (PIRNCA) instrument. Nurs Forum. 2014 Jun; 49(2): 77-87.

21. Schmalenberg C, Kramer M. Types of intensive care units with the healthiest, most productive work environments. Am J Crit Care. 2007 Sep; 16(5): 458-68; quiz 469.

22. Manojlovich M, Laschinger HKS. Application of the Nursing Worklife Model to the ICU setting. Crit Care Nurs Clin North Am. 2008 Dec; 20(4): 481-7.

23. Beaton D, Bombardier C, Guillemin F, Ferraz M. Recommendations for the Cross-Cultural Adaptation of the DASH \& QuickDASH Outcome Measures. 2nd ed. Toronto, Canada: Institute for Work \& Health; 2007. 